\title{
Teaching Evaluation on the Theory and Practice of Control Courses in Complex Networks
}

\author{
Jian Xue ${ }^{1,2}$, Qingyu Zou ${ }^{1,2 *}$ and Ping Xin ${ }^{1}$ \\ ${ }^{1}$ BeiHua University, College of Electrical and information engineering, Jilin, 132021, China \\ bhxuejian@163.com \\ ${ }^{2}$ Jilin University, College of Communication Engineering, Changchun, 130012, China \\ 11496332@qq.com \\ *The corresponding author
}

Keywords: Complex network model; Control curriculum; Theory and practice evaluation system; Teaching evaluation

\begin{abstract}
The control course is an important professional course for engineering students. It is also a course with both theory and engineering practice. Only by combining the theory and practice of the control courses, can we cultivate the comprehensive quality talents with engineering consciousness, practical ability and team cooperation required by engineering education. In this paper, we take the course of "Automatic Control Theory" as an example to analyze the existing problems in the control courses, and put forward the theory and practice of the course optimization program, use the program with complex network model for teaching evaluation. The results show that the reform and optimization program is reasonable and feasible, and can achieve good results.
\end{abstract}

\section{Introduction}

The ultimate purpose of the control courses should be to return to engineering practice, to guide

engineering practice. In the past, teaching and practice mode were single, teaching methods and experimental conditions limited students' learning initiative and learning interest, such as the lack of both theory and practice, theoretical reinforcement not in place, practical ability not in place, inheritance too much, too little innovation and other issues. So optimize the curriculum system, innovative teaching methods and practice teaching reform, so that students can do the class, under the self-study, learning between classes, apply their knowledge, and truly form a "teaching -studying- training - researching - using" line of knowledge is imperative. ${ }^{[1-3]}$

\section{The Main Content of the Study}

Theoretical Teaching. Optimize the teaching content, refine the core of teaching knowledge points. Teaching content optimization is the core of teaching reform, but also determines the theoretical teaching and practice can link successfully. ${ }^{[4,5]}$ The traditional teaching of theory has many drawbacks, such as: the use of mathematical dynamics, theoretical strong, leading to students theoretical practice decoupling. In the reform of teaching content, the main refining the knowledge structure, fit the actual project.

Teaching content optimization diagram shown in Fig. 1: 


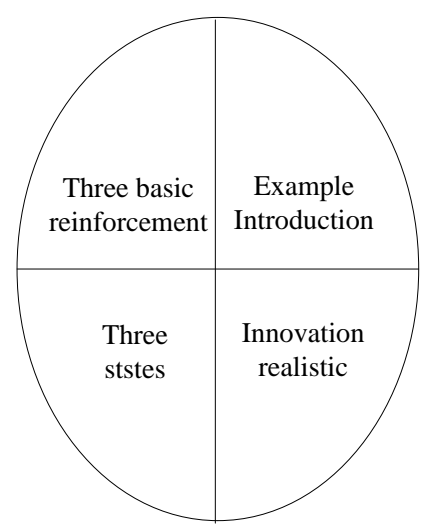

Figure 1. Optimization of teaching content

A Variety of Teaching Methods Fully Integrated. Blackboard teaching, multimedia teaching, network courses and bilingual teaching and other teaching methods are used together, to maximize the current role of teaching resources for students to provide a good teaching environment. Fig. 2 shows a variety of teaching methods and teaching means.

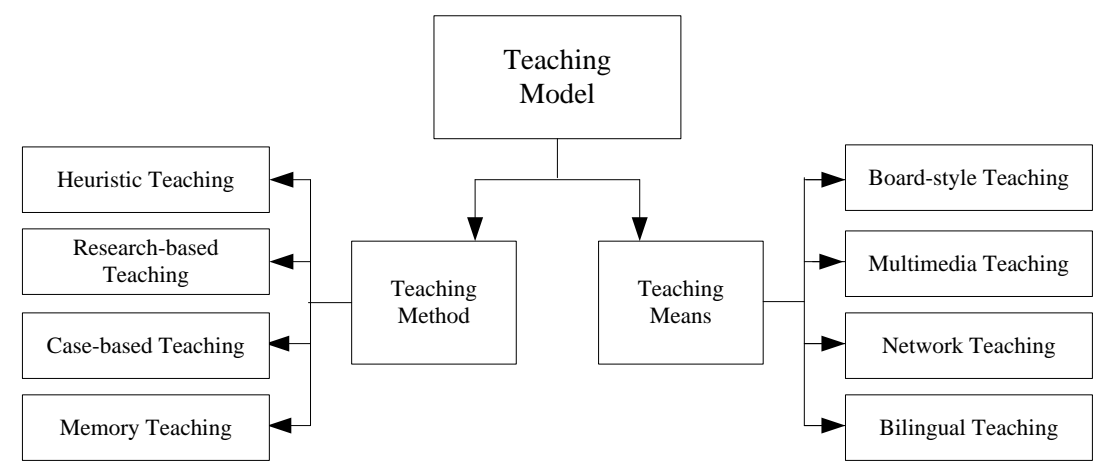

Figure 2. Summary of teaching methods and teaching means

Practice Teaching. The purpose of practical teaching is to cultivate students 'innovative spirit, to inspire students' thinking, to stimulate interest in learning, only to establish a system of practical teaching system, can really adapt to the purpose of training engineering education talents. ${ }^{[6]}$ Specific practice teaching reform can be summarized as Fig. 3:

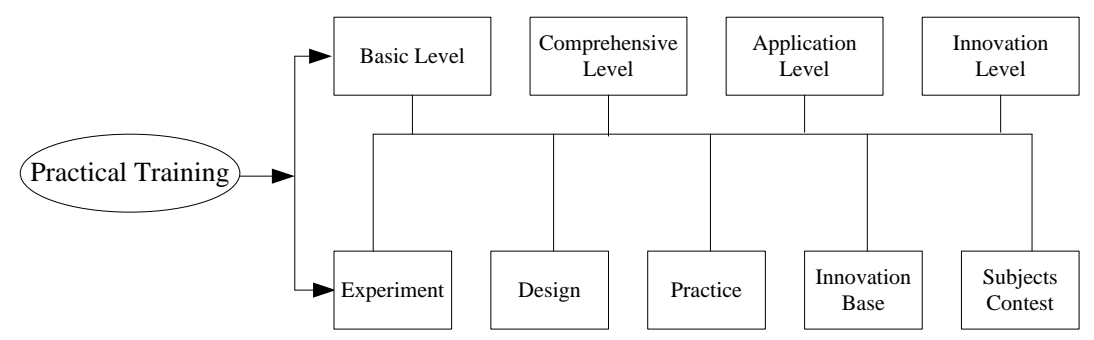

Figure 3. Overview of practical teaching optimization

\section{Establish a Complex Network Model of Course Evaluation Based on RGT Grid Technology}

Kelly Grid Technology (RGT) was first developed by Kelly to elicit and evaluate the relationships between individual constructs. Construction of complex network model of teaching evaluation is divided into three steps: peer response、Calculate the edge weights、generate a network model. ${ }^{[7-10]}$ The results are shown in Fig. 5 and Fig. 6. 

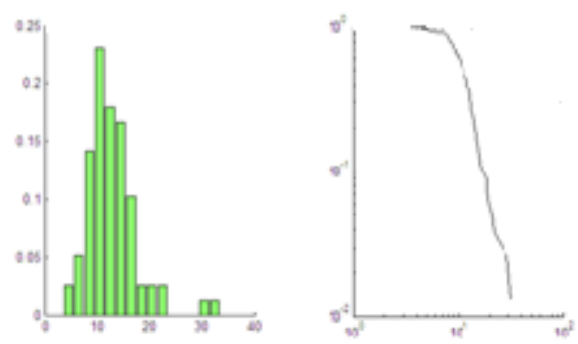

In-degree distribution
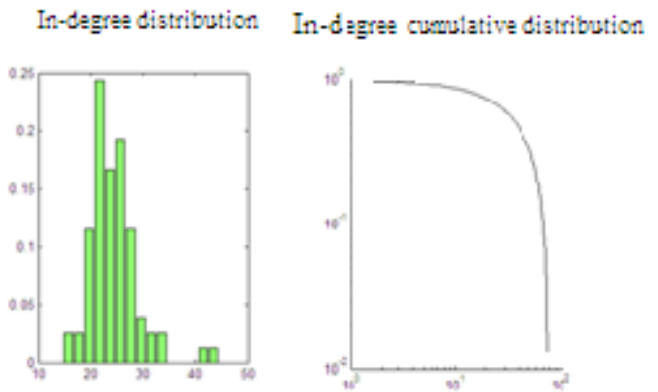

Degree distribution

Degree curvilative distribution

Figure 5. Distributions and cumulative distribution of in-degree and degree of teaching evaluation network of "automatic control theory" course

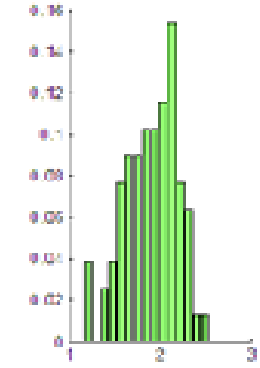

In-closeness distribution

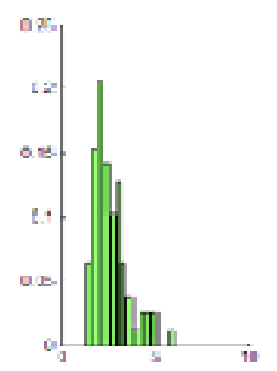

Closeness distribution

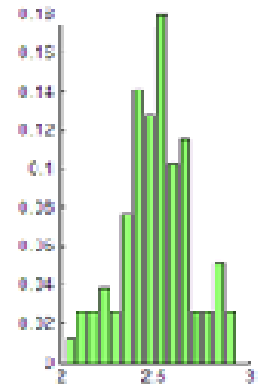

Out-closeness distribution

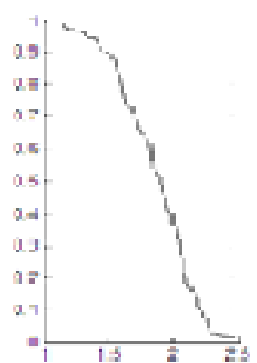

In-closeness cumvlative distribution

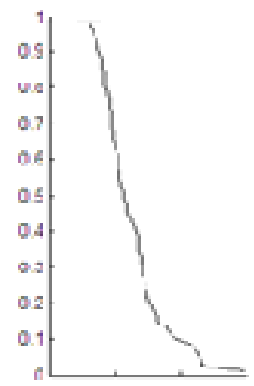

Closeness cumulative distribution

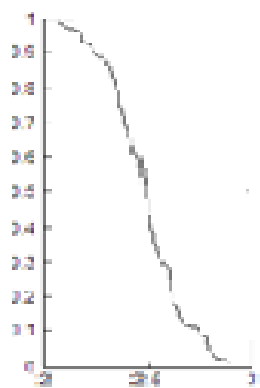

Out-closeness cumvlative distribution

Figure 6. Distribution and cumulative distribution of in-closeness, out-closeness and closeness of teaching evaluation network 
From the degree of distribution and cumulative distribution of most students in the learning situation in the upper level, indicating that the majority of students to absorb the most of the knowledge, some students learn the situation of good students. As we can see from in-closeness, closeness, out-closeness, they follows a normal distribution. most of the students' proximity is between 1.6 and 2.3. It shows that most students have similar learning situation, and receive better knowledge information from the cumulative proximity distribution The distribution of learning situation is more uniform

\section{Conclusion}

In the teaching of engineering courses, we must uphold the principle of equal emphasis on theory and practice so that students maximize access to learning knowledge, lay the foundation for future work and further study. The use of Kelly grid technology makes the evaluation of educational effects play a very good evaluation of our reform .there are still many shortcomings, such as Individual students still can't be a good absorption of knowledge practical ability is not strong, In the future teaching, we must increase the teaching methods and teaching means of reform and investment, and further improve the undergraduate control courses.

\section{Acknowledgements:}

This work is supported by :

1.BHDQ31.Jilin province, Jilin, BeiHua University

2.Jilin Province Department of Education Science and Technology Plan Projects. (201658)

3. Jilin Province Department of Education Science and Technology Research Project(201656)

\section{References}

[1] $\mathrm{Hu}$ Wenlong, Based on the CDIO engineering inquiry teaching reform research; higher engineering education research.2013.5:163-168

[2] $\mathrm{Gu}$ Xueyong, the theory and practice of linking the CDIO-Tsinghua University to explore innovative engineering education; Higher Engineering Education Research; 2013. 5: 11-23

[3] Lei Huan, Tang Wei Yi, Edward F. Crawley; training innovative, multi-level, professional engineering and technical personnel - CDIO engineering education reform talent concept and training mode; Higher Engineering Education Research; 2009. 7:29-35

[4] Dong Zengwen, Deng Xiaohua, Zhang Hua; Research and teaching in engineering education practice and reflection; Higher engineering education research; 2013. 1: 164-167

[5] L. Darling, A. Jaquith, and M. Hamilton, Creating a Comprehensive System for Evaluating and Supporting Effective Teaching. Stanford, CA: Stanford Center for Opportunity Policy in Education, 2012.

[6] P. B. Stark and R. Freishtat, An Evaluation of Course Evaluations, Science Open Research, 2014: 1-26, 2014.

[7] K. Peterson, Teacher Evaluation: A Comprehensive Guide to New Directions and Practices, Corwin Press, Inc., 2000.

[8] J. E. Koppich and D. C. Humphrey, Getting Serious About Teacher Evaluation, Education Week, 31(7):25-28, 2011.

[9] J. Embacher and F. Buttle, a Repertory Grid Analysis of Austria's Image as a Summer Vacation Destination, Journal of Travel Research, 27(3): 3-7, 1989. 
[10]F. B. Tan and M. G. Hunter, The Repertory Grid Technique: A Method for the Study of Cognition in Information Systems, MIS QUARTERLY, 26(1): 39-57, 2002. 